\title{
Integration as Didactic Prerequisite for Creating Situations of Axiological Choice to be Made by Students
}

\author{
Zinaida Brizhak ${ }^{1}$, Karina Kolesina ${ }^{2}$, Natalya Mironenkova ${ }^{3 *}$ \\ ${ }^{1}$ Rostov State Medical University, Rostov-on-Don, Russia \\ ${ }^{2}$ Southern Federal University, Rostov-on-Don, Russia \\ ${ }^{3}$ Platov South-Russian State Polytechnic University, Novocherkassk, Russia
}

\begin{abstract}
Schooling helps to take on the image of "Self" by integrating the meanings and narratives of our culture, identifying oneself with its values, including social ones. Integration is viewed by the authors as a process bringing multifarious meanings together, into a single interface between the meanings of various subjects and objects of the pedagogical process. It is proved that such approach encourages students to make a certain axiological choice, the first manifestation of meaning. Selected elements of pedagogical process - problems, problems-antinomies, events, concrete facts, personalization - combine various contents, make them into a single whole, creating prerequisites for axiological choices. It was found that the greater is the meaningful potential of integrated knowledge in the choice situations, the higher is the personal relevance of the problem for the student; events, specific facts and "acting out the characters" should affect the emotional and aesthetic sphere of the student. Due to this the axiological choice will be based on inner emotion, experiencing which is an indispensable prerequisite of personality development
\end{abstract}

\section{Introduction}

The world is a holistic system with a variety of interrelated elements, one of which is a human being. The world in which the man lives is one single whole, that is why the way we perceive it and learn about it has to be holistic and systemic. However, the composition of educational medium (subject-centered) imposes a certain fragmentation on the teaching mode, which prevents educators from achieving the global goal of education - the all-round development of students [1,2]. At the same time, graduates are supposed to be able to adapt to various real-life situations, to single out, summarize and generalize information that keeps building up due to the advancement of knowledge and science. Most importantly, they are not to get lost in the multitude of this holistic system's components, and are to discover their own personal meaning by way of making axiological choice.

\footnotetext{
*Corresponding author: vin-mir@bk.ru
} 
The life journey of a person is determined by their choice, and the choice is determined by priorities in meaning. Even if the person goes against their own meaning, this behavior also has a meaning of its own. Every person's life is shaped by their own choices [2, 3]. Hence, it is possible to attach personal meaning to the learning process by involving the subjective attitude of the student who contributes to their own learning process by creating situations of axiological choice, based on an integrated approach. The axiological choice made by students within the framework of the learning process can be extended through cross-subject integration of forms and ways of activity, teaching materials, or an in-depth vertical study of the subject.

In terms of modern psychological and pedagogical research it is the cross-curricular integration that prompts the initiation of meaning, the collation of cultural values, the meaning-making, the shaping of a coherent world view of the student $[1,4,5]$. Interdisciplinarity in teaching enhances student's creativity of thinking $[6,7,8]$. Creative activity, in its turn, enriches the domain of meaning in the life of a human being. For example, Victor Frankl identified the values that enable a person to adopt a life stance and make their life meaningful: creative values, experiential values and attitudinal values [9, p.15]. Frankl gives priority to creative values.

Holistic education is capable of reintroducing the "spiritual dimension" into education and resolve the major problems of modern society: degeneracy, disregard for culture, traditions and values [10]. Such education can make a person feel free mentally and spiritually, thus giving them freedom of choice. There was a good reason, therefore, for Howard Gardner to put forward the idea of multiple intelligences (linguistic, logicalmathematical, intra-personal, interpersonal, musical, bodily-kinesthetic and spatial types of intelligence) relating them to various learning opportunities for students [11]. This brings to the fore the axiological development of a person with emphasis on the emotional and the sensuous, rather than the student's cognitive development. It follows that the system of teaching employing situations of axiological choice made by students should equally comply with both rational and spiritual dimension, and meet students' various needs, with the principle of integration being a prerequisite for implementing the whole system. For example, mathematics can be integrated with music and literature. Clearly, it is a challenging task to design a cross-curriculum course of mathematics within the current system of teaching, yet a single lesson or even part of the lesson seems a viable option.

\section{Results and discussion}

Growing interest in the integrated approach within the framework of meaning-making approach is associated with the cultural-anthropological personality-oriented system of education introduced by E.V.Bondarevskaya [12]. Its elements, teaching, student and teacher, underlie the conceptual framework of this system, where education is viewed as the process of culture acquisition through personal meanings, cooperation and dialogue; student is treated as the subject of education, capable of cultural self-development and possessing their own system of values, and teacher is understood as a link connecting students and culture, the one who introduces them to the world of culture (that is, values and meanings). According to E.V.Bondarevskaya, in the course of teaching and learning activities the student's public experience comes into contact with their individual experience, the former being a reflection of rules, regulations and patterns of cultured life, and the latter - the child's subjective experience, which means that meaning is created in the situations of making choices, when private and public daily living are integrated into one.

When creating axiological situations of making a choice we view integration as a means, a precondition due to which it is possible to perceive the student's personal meaning, transform and enrich it in order to better meet their needs, satisfy their interests and fulfil their potential [13]. Note, however, that the concept of "integration", when 
applied to the system of teaching, may be twofold, viewed as the learning objective ("intended to create a whole picture of the world") and the learning tool ("intended to gain, extend and broaden knowledge") [14].

Integrated approach enables students to shape alternative thinking, which is indispensable in the modern world. "Alternative thinking means freedom in assessing facts and events, freedom from back-to-basics approaches, and true democracy" [1, p.82]. There is no choice without alternatives, and although there is such a thing as Hobson's choice, its meaningful potential is reduced to a minimum due to the fact that there are either no options at all, or they are equivalent and have an equal ranking, meaning-wise. Integrated teaching and learning process creates conditions for the student to see something more significant, an event horizon, which is very important for a meaningful choice. In the paper by Jasmin Godemann it is pointed out that ability to see beyond one's own disciplinary boundaries, to ponder on the processes of knowledge integration, to accept new ideas, as well as self-reflection, are the skills the person acquires when an integrated approach is adopted in teaching [15]. Actually, any framework does impose a limit on meaning-making, and it is only self-reflection (reflexive pause) that gives you a chance to "listen to your heart". "Making a choice is taking a reflexive pause, "being passive actively". The choice the person has made limits the realm of their existence, restricts the superfluous world around, but by doing this they "define" themselves as a personality" [16, pp.67-68].

I.S.Dyshliuk treats integration as the leading form of organizing educational content, because the laws of nature are universal and uniform, and the subject consistently perceives the world around; integration creates more ample opportunities for creating a single meaningful space and developing students' ability of meaning-making [4]. The author singles out factors of interdisciplinary integration, that is, those constituents which can bring together a variety of contents, shape a manifold, and thus create prerequisites for meaningful space. They are: the subject matter and the problem area, specific fact, major concept, ideas, theories underlying the course of study, content personalization.

However, the point in question is when exactly during a class an integrated content can generate situations of choice for students. One of such pedagogical components is a problem. Both the problem itself and its respective structural unit - a problem-based situation - have the greatest meaning-making potential and lead to the highest structural level at which one can discuss the problems related to universal human values. The problems touch the chord with every student thanks to the student's personal experience and their value-oriented attitude to the world and to oneself. Whatever the case, the problem should be of personal importance for the student, and to resolve it they have to apply both the previously acquired knowledge and skills, manifested in their experience, and some new knowledge still to be gained. This situation may be called an "encounter" between the imposed and the subjective experience relevant to students.

John Dewey was one of the first educators who came up with the idea of incorporating real-life problems into the teaching and learning process and subsequently looking for solutions beyond the scope of one subject [17]. According to Dewey, teaching is to be planned with an account of the students' abilities, as well as their previous and current experience; while teacher is expected to develop their problem-solving skills. The primary objective for the teachers is to give greater freedom to children for the latter to explore their environment. He was a proponent of an interdisciplinary curriculum, or just the one that focuses on integrating several subjects, with students entering and leaving their classroom freely just because they are pursuing their interests and following their own paths of knowledge acquisition and application. Dewey's ideas give us an understanding of integration as an opportunity to give students freedom in choosing the ways and means to solve personally important problems in the course of learning. 
The learning process acquires a great momentum if the already gained personally important information contradicts the incoming information. In this connection it is quite practical to discuss problems-antinomies, which are an extreme form of inconsistency, a "combination of something that cannot be combined". Antinomies can cause conflict between the actualized meanings, which are present in the students' experience, and the potential meanings present in the teaching content. Content integration in this case creates conditions for appraisal activity followed by adopting a standpoint, or conditions for putting forward a new idea or a problem. Meaning is created at the interface between materials from different domains. In mathematics examples of such antinomies are: addition or detraction; differentiation or integration; symmetry or asymmetry; convex or concave surfaces etc.

Event (specific fact) is another component which attracts content from different domains. Ancient Greek philosophers related the choice that the person makes in life with the turning points or crises in their lives. The word "crisis" is derived from the Greek krisis "decision", from krinein "decide". According to William C. Schutz, the common feature of all crises is the fact that every crisis involves having to make a choice [18]. Crisis used to be called a "herald of coming changes", as it implies being unhappy with the present, re-thinking of meanings and values, as well as the willingness to change the situation. However, it is the event, which is the cause of every crisis (choice). The event creates certain space for convergence of traditions, culture, social experience and actualized meanings. The event must leave an imprint, give some experience, arouse some emotions and feelings. It is best when facts pertain to moral values or vital issues, as an "encounter with a certain value" expands the space within which the student feels psychologically free to make their choice. Events within the framework of learning process can be exemplified by instances of wars, natural disasters, victories, scientific breakthroughs, historic events, natural phenomena.

Within the scope of an event there are two modes for the student to choose from, a passive and an active one. In the former case the teacher just waits for the student to perceive facts and to respond, and then engages them in a dialogue or a conversation. In the latter case students get closely involved in the activities devoted to different events. For example, a festival celebrating friendship between different peoples of the country integrates several areas of knowledge. History classes may help to learn the customs and traditions of different peoples, physical geography will enable to describe the country's location, music classes will teach children to sing the traditional songs and tunes of the land, arts and crafts class will introduce students to artefacts and household items and teach some traditional practical skills. Such activity enables students to come up with the understanding of actualized meanings and register some essential common features, which leads to meaningful generalization and then axiological choice. This is, in fact, the activity that shapes a coherent picture of the world.

Self-assertion and self-fulfilment are gained through culturalization and personalization of the subject (an individual) [19]. Culturalization is related to object-transformational activity and results in creating objects of material and intellectual culture. Personalization of an individual is an extension of their existence, an expression of their individual representation, their otherness in other people - that is, it is the process of the object-intosubject transformation, the subject having discovered their personal identity and their personal meaning. However, it is impossible to shape your "individual destiny" and build your educational trajectory, relying only on your individual features and qualities, both without making axiological choice and integrating content, because the more characters and roles are available, the easier it is for the student to find the one that appeals to them. Note that, according to a definition from a dictionary of psychology, integration is viewed as the creation of internal unity and togetherness, which is expressed in the understanding of the 
collective togetherness of the group as its unity in terms of values and orientation, and in terms of objectivity when taking on the responsibility for the successes and failures of the group. Thus, integration is a tool that makes it possible to bring together in a "knot" the issues of morality and the issues of egocentrical meanings. Integration-wise, personalization in the learning process can be exemplified by such activities as fairy-tale lessons, real-life characters enacted by students, or festivals. The most important thing here is to organize group activities and subsequent discussions aimed at reflecting on the significant "personal contributions" when students choose this or that personal trajectory.

\section{Conclusions}

Thus, practically every day the person is confronted with various problems resonating with the student's personal experience. Problem-based situations created in the course of studying a discipline make it possible to approach the natural processes of life's activity, especially when such situations involve the real life of the individual.

Problems-antinomies contain some paradox, bring the impossible together and join the unjoinable. This leads to the understanding and acceptance of the meanings of the others, but, more often, it brings about a new meaning, and antinomies, because of their controversial nature, facilitate the process.

An event (a specific fact of life) becomes a multifarious space within which traditions, culture, social experience and actualized meanings come together. Such approach gives every student an opportunity to discover and actualize their own self.

Personalisation gives the student a chance of living out and acting out in a different context, which encourages their meaning-making activity. The student gains a different personal experience and, which is more important, expresses themselves, having discovered a new meaning.

Note that the way out of any situation (problems, problems-antinomies, events, specific facts, personalization) is to be found within the person themselves, through emotional experience, and is to affect the emotional and aesthetic sphere of the individual. It is only in such context that a person can identify the true values and create or enrich their meanings. This means that the major task of the teacher is to create this inner emotion, which facilitates search for truth as the students are confronted with different opinions, judgements, and attitudes. It is only such (problem) situations that can generate certain "crisis spots", going through which is an indispensable prerequisite of personality development. In the proposed perspective, integration as a sine qua non in creating situations of choice expands the meaningful space of students due to a variety of subjects making up the content of learning, and, which is of utmost importance, facilitates the occurrence of lofty meanings, existential meanings, pro-social meanings, which are all described by an inner meaningful focus on achieving the outcomes that will do good and promote the welfare of the people, the society, and the mankind.

\section{References}

1. I. Abakumova, P. Ermakov, V. Fomenko. Russian Psychological Journal. 11, 14 (2014)

2. I. Abakumova, E. Zorina. IJCRSEE. 5, 41 (2017)

3. N. Mironenkova. Azimuth of Scientific Research: Pedagogy and Psychology, 8, 158-161 (2019)

4. I. Dyshlyuk. RPJ. 11, 41-48 (2014)

5. I. Dyshlyuk, I. Kameneva, A. Moskalenko. RPJ. 1. 96-107 (2017) 
6. D. Pennington, G. Simpson, M. McConnell, J. Fair, R. Baker. BioScience. 63, 564-573 (2013)

7. M. López-Huertas. Knowledge Organization. 40, 400-407 (2013)

8. B. Nicolescu. Transdisciplinary Journal of Engineering \& Science. 1, 19-38 (2010)

9. V. Frankl. Psychotherapy and existentialism (Simon and Schuster, New York, 1967)

10. V. Chtchyan. International Journal of Humanities and Natural Sciences, 4, 135-138 (2019)

11. H. Gardner. Intelligence Reframed: Multiple intelligences for the 21 st Century (Basic Books, New York, 1999)

12 E. Bondarevskaya. Izvestya Volgogradskogo Gosudarstvennogo Pedagogicheskogo Universiteta. 3, 4-14 (2016)

13. N. Mironenkova, I. Rudakova. Vestnik Tcherepovetskogo Gosudarstvennogo Universiteta. 2. 114-118 (2011)

14. Yu. Kolyagin, O. Alekseyenko. Nachalnaya Shkola. 9, 28-31. (2001)

15. J. Godemann. Environmental Education Research. 14, 625-641 (2008)

16. N. Noskova. Vestnik Pravoslavnogo Svyato-Tikhonovskogo Gumanitarnogo Universiteta. 3, 59-70 (2008)

17. A. Sikandar. JoEED. 2, 191-201 (2015)

18. V. Schutz. Choice. Deep simplicity: foundations of social philosophy (Rosa Mira, St. Petersburg, 1993)

19. A. Petrovskij, V. Petrovskij. Voprosy Filosofii. 3, 44-53 (1982) 